\title{
Healthcare needs of vulnerable patient groups: available data and existing gaps in Germany with respect to long-term mechanical ventilation
}

\author{
Susanne Stark ${ }^{1}\left(\mathbb{D} \cdot\right.$ Michael Ewers $^{1}$
}

Received: 29 October 2018 / Accepted: 5 March 2019/Published online: 21 March 2019

(C) Springer-Verlag GmbH Germany, part of Springer Nature 2019

\begin{abstract}
Aim Long-term invasively ventilated patients exhibit exceptional and resource-intensive healthcare needs. However, major knowledge gaps in Germany complicate appropriate approaches to best address these demands. This paper evaluates available information on the patient group and their healthcare needs from German data sources and derives implications for healthcare planning and regulation by national/federal self-governing bodies, political decision-makers, and specialized providers.

Methods Based on the concept of needs, we addressed the normative dimension typically characterized by epidemiological data. Based on existing German health system data resources, an explorative approach was utilized to identify and characterize available databases providing information on the patient group and/or their healthcare.

Results To date, no available database provides information on the healthcare needs of this patient group. As of the reporting year 2017, the diagnosis-related groups (DRG) statistics will provide hospital-specific data on home invasive ventilation interventions, but the data do not provide information on long-term care. Claims data may be a promising source for cross-sectoral evaluation of healthcare needs but feature methodological challenges. These results call for efforts to address limited data eligibility, adopt a broader understanding of healthcare needs, and identify actions needed to evidence informed and needsoriented healthcare.

Conclusion Future approaches on needs-oriented specialized healthcare should close the existing knowledge gap based on reliable data. In addition to normative information, they should consider subjective dimensions on a life course perspective and quantitative and qualitative service performance characteristics across multiple sectors and professions.
\end{abstract}

Keywords Healthcare needs $\cdot$ Healthcare epidemiology $\cdot$ Concept of needs $\cdot$ Long-term invasive ventilation · Data availability

\section{Introduction}

Needs orientation in healthcare planning, regulation, and provision is internationally highlighted as essential to integrated and people-centered health service delivery in the context of the demographic and epidemiological shift (World Health Organization, WHO 2015). Despite ongoing debates about the concept of needs and its use regarding equity in resource allocation and needs assessment, it is widely utilized to

Susanne Stark

s.stark@charite.de

1 Charité-Universitätsmedizin Berlin, corporate member of Freie Universität Berlin, Humboldt-Universität zu Berlin, and Berlin Institute of Health, Institute of Health and Nursing Science, Augustenburger Platz 1, 13353 Berlin, Germany discuss and justify decision-making about healthcare priorities and services (Daniels 1981; Godfrey and Callaghan 2000).

The German Healthcare Advisory Council has also called for needs-oriented healthcare planning and provision for years, especially for complex and vulnerable patient populations (Sachverständigenrat zur Begutachtung der Entwicklung im Gesundheitswesen, SVR Gesundheit 2018). However, current approaches are highly selective, restricted to medical care, and methodologically imprecise (Ozegowski and Sundmacher 2012; SVR Gesundheit 2014). Underlying theoretical assumptions usually refer to the normative dimension within the concept of (healthcare) needs. It represents an objectively (by experts, professionals, and scientists) justified need for a certain intervention due to a certain condition (e.g., Bradshaw 1972; Daniels 1981). This approach is criticized by some authors, as it forces unidirectional needs assessment by professional judgements (e.g., Bradshaw 1972; Godfrey and 
Callaghan 2000) and neglects subjective (felt) needs dimensions that also determine service demand and utilization (Bradshaw 1972) based on experience, expectations, knowledge, or preferences (Godfrey and Callaghan 2000). As a result, current approaches may reinforce a silo mentality and negate the multidimensionality of healthcare needs. This is particularly challenging with vulnerable patient populations, which often feature particular needs for continuing complex healthcare in differing settings and from varying professions (e.g., WHO 2015).

One of these highly vulnerable populations is long-term invasively (i.e., via tracheostomy) ventilated (LTIV) patients in need of intensive medical and nursing care beyond acute episodes of illness. This patient group features a rapid growth (e.g., Deutsche Gesellschaft für Pneumologie und Beatmungsmedizin, DGP 2017) and considerable quantitative and qualitative resource utilization. The patients usually face high dependency on technical and professional support (DGP 2017; Deutsche Interdisziplinäre Gesellschaft für Außerklinische Beatmung, DIGAB 2017; Lewarski 2005) and a need for continuing, multisectoral, and interprofessional healthcare (Lewarski 2005; Lehmann et al. 2016; DGP 2017). However, these patients in Germany are typically cared for in settings not prepared or suitable for these requirements, such as private homes, shared apartments, or, infrequently, nursing homes. Meanwhile, increasing political attention and research activities reveal issues concerning inappropriateness, fragmentation, and regional variation of specialized services, marketdriven service development, inadequate professional qualification, and poor outcomes of specialized healthcare (Lehmann et al. 2016; Stark et al. 2016).

However, the German discourse on the specific needs of and adequate care approaches for the patient group is currently in its infancy. It is built basically on outdated (e.g., LloydOwen et al. 2005) or vague population estimations (e.g., DIGAB 2017). By contrast, other countries such as Norway (Tollefsen et al. 2009), Sweden (Midgren et al. 2000), and Poland (Nasiłowski et al. 2015) have already made various efforts to gather needs- and healthcare-related information on the patient group, leading to broad discourses on needs orientation in healthcare.

A thorough understanding of needs as well as the structures, processes, and outcomes of specialized healthcare is required to evaluate whether current services can meet the needs of LTIV patients. The explorative study "Healthcare for long-term ventilated patients - regional aspects" (VELARegio) aimed to elucidate these aspects (Lehmann et al. 2016). This paper aims to illustrate study results that explored available information on healthcare needs of the patient group. We asked which identifiers obtained from German data sources may enable (partial) description of LTIV patients. The results guide implications on needs-oriented healthcare through service providers and on healthcare planning and regulation by accountable self-governance bodies (e.g., regional statutory long-term care funds/associations of statutory health insurance physicians, states) and political leaders.

\section{Methods}

We adopted an explorative approach to identify available and accessible data sources according to the normative dimension of the concept of (healthcare) needs. Despite the limitations mentioned above, this dimension is widely utilized for needsoriented healthcare planning and regulation, as individually perceived needs are not considered to be representative of "real" needs (e.g., Bradshaw 1972; Daniels 1981).

In order to identify healthcare needs, we had to approximate via healthcare epidemiology due to the remarkable epidemiological heterogeneity of the patient population (Lloyd-Owen et al. 2005). This was achieved using the interventional indicator of "long-term invasive ventilation" (identifier). Consequently, according to the current German guideline (DGP 2017) and recommendations on home invasive ventilation (Randerath et al. 2011), the patient group in need was defined as adult patients with continuing dependency on invasive ventilation due to chronic respiratory insufficiency. Continuing dependency exists if the individual requires intermittent or continuous invasive ventilator support ("unsuccessful weaning"; Schönhofer et al. 2014) in the private home, shared apartments, or nursing home settings. The particular vulnerability of these patients results from a significant severity of underlying diseases with dependency on continuing specialized care due to the likelihood of life-threatening incidents and the loss of self-governance (Randerath et al. 2011). Consequently, patients are usually entitled to specialized nursing care services in community settings (home or shared apartment) or nursing homes according to $\$ 37(2)$ German Code of Social Law V (Sozialgesetzbuch V, SGB V). Patients not meeting this vulnerability criterion were excluded. This also applies to children and adolescents due to significantly differing morbidity (DGP 2017).

This interventional approach on healthcare needs implicates an ex ante exclusion of data sources focused exclusively on diseases or healthcare services/facilities/personnel. Potentially suitable sources were identified according to the German Federal Health Monitoring (Gesundheitsberichterstattung, GBE) and existing expert reports on German health system data resources (Robert Koch-Institut, RKI 2011; Swart et al. 2015). The eligibility of data sources was assessed descriptively by screening for the identifier. If available, additional conditionspecific epidemiological measures (incidence/prevalence) were extracted to characterize normative healthcare needs. We additionally reviewed eligible databases for further needs indicators, such as demographics (age, sex, place of residence), morbidity (main/secondary diagnoses), and spatial context 
(e.g., RKI 2011). Supplementary basic characteristics (type of assessment and inventory, spatial reference, periodicity, availability, access) of eligible data sources were reported. The results are differentiated according to the sectoral origin of data (inpatient, long-term care, cross-sectoral).

\section{Results}

Publicly accessible databases or registers (Table 1) providing epidemiological information on LTIV are currently not available in Germany. Prospectively, data on the prevalence and incidence of the patient group will be available from the federal statistics on diagnosis-related groups (DRG) statistics, as they have been supplemented by specific operation sets since 2017. The data sources identified with general relevance for needs assessment and their current challenges are presented below. All but the source of cross-sectoral health insurance data represent official German statistics regarding either the inpatient (hospital and DRG statistics) or the long-term (nursing care and KG 2 statistics) care sector.

\section{Inpatient care}

\section{Hospital statistics: basic data}

The federal hospital statistic is an annual, complete primary inventory on the characteristics and utilization of hospitals, prevention and rehabilitation facilities. Data account for, amongst others, the number of cases of mechanically ventilated patients in intensive care settings on a federal and state level (Statistisches Bundesamt 2017a). Although long-term care for these patients is conducted primarily in home care settings, the hospital statistic is generally of central relevance to epidemiological data collection, since the case-based incidence and prevalence of LTIV, morbidity, and discharges may be determined by typical classification (e.g., ICD-10-GM code, such as Z.99). However, the hospital statistic currently neither specifies hospital discharges with ventilator support nor differentiates between different types of ventilation (invasive/noninvasive).

An inpatient register on epidemiological, healthcare, and outcome-related data on prolonged ventilation and weaning efforts (e.g., diagnoses, ventilation parameters, weaning procedures, outcomes, complications) is operated by WeanNet, a German competence network of pneumological weaning units. The network aims to improve hospital care and outcomes of ventilated patients (Schönhofer and Pfeifer 2010). However, this non-official database also does not provide post-discharge or long-term monitoring on LTIV beyond hospital care, and exclusively comprises data from registered pneumological weaning centers.

\section{DRG statistics}

The DRG statistics provide complete annual inventory data on the characteristics, diagnoses, and procedures of inpatient hospital care according to $\$ 21$ KHEntgG (Krankenhausentgeltgesetz), irrespective of health insurance type. This secondary statistic may serve as a basis to describe the epidemiological features of the patient group, although it primarily focuses on the hospital sector. A relevant indicator within the underlying operation and procedure code (Operationen- und Prozedurenschlüssel, OPS) is "Setup of artificial respiration at home" (8-716). This code describes an intervention to prepare for the discharge of a ventilated patient. Until 2016, this OPS code did not differentiate between invasive and noninvasive ventilation modes (Gesundheitsberichterstattung des Bundes, GBE Bund 2016). This code was restructured with the OPS update in 2017 regarding two aspects that prospectively enable the detailed coding of LTIV: (1) the OPS now distinguishes between invasive and noninvasive ventilation modes and (2) sub-codes distinguishing between the "initial setup of long-term invasive ventilation at home" (8-716.30) and its "control/optimization" (8716.31) are now available (Deutsches Institut für Medizinische Dokumentation und Information, DIMDI 2016).

These indicators prospectively enable both the determination of the number of new (incidence) and existing cases (prevalence) of hospital discharges on a national, federal, and local level, as well as their changes over time. This enables the assessment of healthcare needs and their stratification based on additional indicators (demographic, morbidity [ICD-10-GM main/secondary diagnoses], length of stay, standardized operations and procedures during the hospital stay in certain specialty departments, official DRG lump compensation, reason for discharge/transfer [Statistisches Bundesamt 2018]). However, these data do not allow one to follow patients in the community setting or to determine their degree of vulnerability and associated needs according to §37(2) SGB $\mathrm{V}$. Therefore, information on medical and nursing care, medical supplies, or the time course of healthcare beyond hospital discharge need to be linked.

\section{Long-term care}

\section{Medical care}

Data on medical interventions for LTIV patients provided by general practitioners or medical specialists in long-term care settings are currently not available. Three periodic secondary statistics with possible relevance for needs assessment are available: (1) the statistics on medical account cases (KG 3 statistics) from the Federal Ministry of Health (Bundesgesundheitsministerium, 


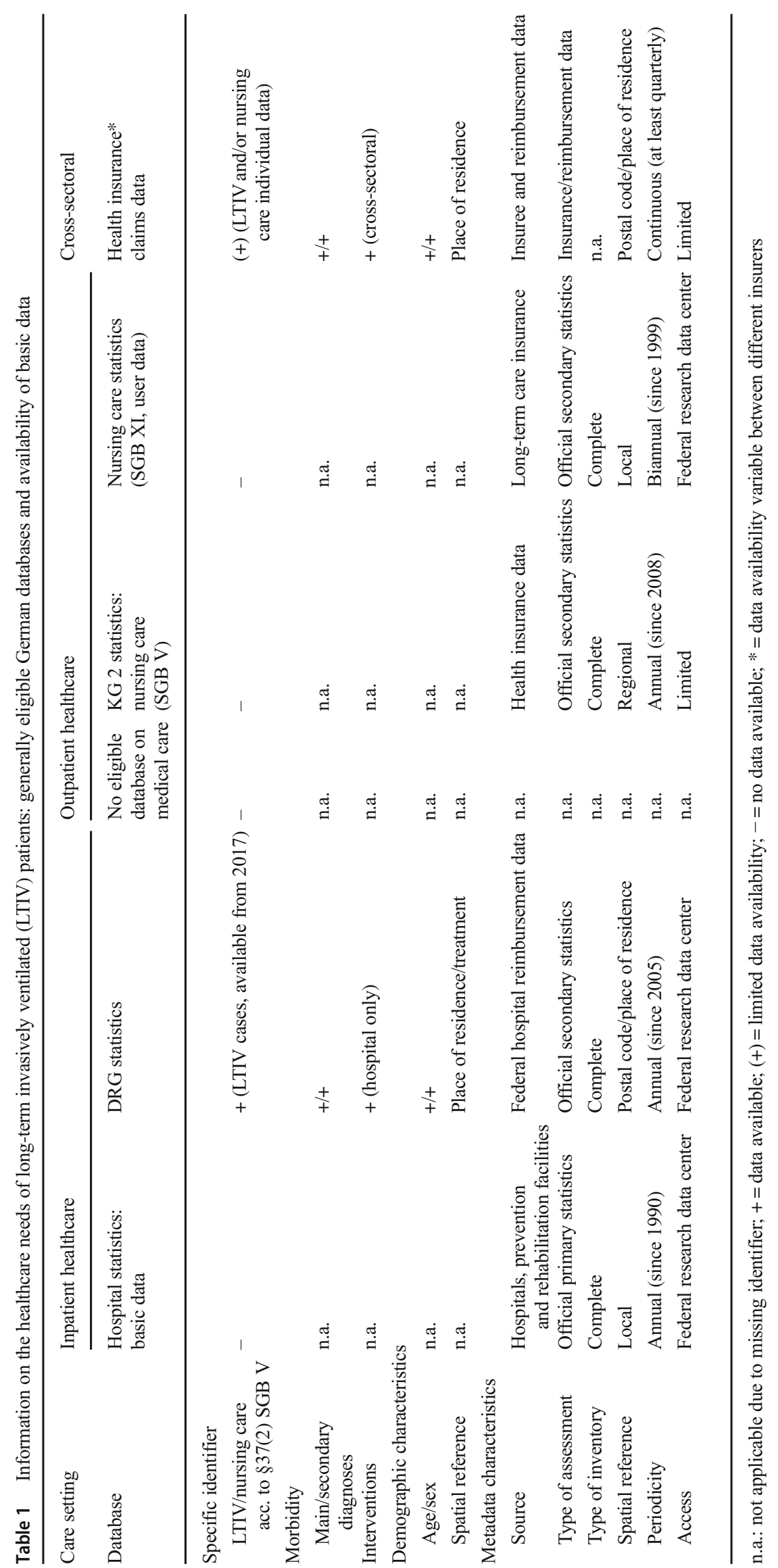


BMG), (2) the statistics of the statutory medical services of the National Association of Statutory Health Insurance Physicians (Kassenärztliche Bundesvereinigung, KBV), and (3) the health expenditure calculation (regarding special medical supplies) of the Federal Statistical Office. However, none of these data sources provides indicators on medical interventions specifically attributable to LTIV. Furthermore, all of these sources aggregate relevant topics to a comparatively high level, not allowing for single intervention or supplies analyses, respectively.

\section{Nursing care statistics}

Nursing care demand and supply are analyzed in the biennial nursing care statistics according to user characteristics, place of residence, and supply characteristics (complete inventory). Data derive from statutory and private long-term care insurance (secondary statistics). They enable small area analyses (Statistisches Bundesamt 2017b). Since LTIV patients are usually given a care level according to $\S 14$ long-term care insurance law (SGB XI), the nursing care statistics are generally suitable for providing information about the nursing care of LTIV patients. However, the data available are neither differentiated in terms of other than general nursing care groups (care setting, level of care) nor with respect to morbidity (e.g., respiratory insufficiency) or interventions (e.g., invasive ventilation). They are, thus, inappropriate to describe the patient population.

\section{KG 2 statistics: home nursing care}

The second data source on nursing care is the annual statistics on claims and benefit days (Leistungsfälle und -tage [KG 2]), based on statutory health insurance data (complete inventory, no private insurance data). It provides case-based data on home nursing care according to SGB V (health insurance coverage; a differing funding scheme to nursing care according to SGB XI; funding according to SGB V and XI can exist in parallel) regarding the type of insurance (Bundesministerium für Gesundheit, BMG 2017). LTIV patients are frequently eligible for home nursing care due to their need for ongoing intensive care after hospital discharge. This specialized type of nursing care is regulated by $\$ 37(2)$ SGB V in conjunction with the Federal Directive on Prescription of Home Nursing Care (Häusliche Krankenpflege-Richtlinie [HKP-RL]) attachment no. 24 (special observation of the sick [Spezielle Krankenbeobachtung]) (Gemeinsamer Bundesausschuss, GBA 2018) and approvable to patients in home care settings and those living in nursing homes.

The KG 2 statistics, therefore, has a fundamental importance for describing special claims and benefits that enable conclusions to be made on the healthcare needs of the patient group. However, although the source provides data on nursing interventions according to $\$ 37(2)$ SGB V, the data are inappropriate for utilization on the special patient group for two reasons: (1) the cases assessed only include patients in home care settings; those in nursing homes are neglected and (2) the reason for home nursing care (i.e., LTIV) as legally approved is not specified (BMG $\S 37(2)$ ). Thus, the patient group of interest is disregarded within these data.

\section{Cross-sectoral health insurance claims data}

Individual health insurance data generally offer a wide variety of information on the insurees and their healthcare utilization, regardless of the healthcare sector (Schubert et al. 2014; Swart et al. 2015). Therefore, they create a source for the analyses of healthcare needs and broader research questions. However, and despite these inherent advantages, insurance data feature three considerable access disadvantages. (1) Claims data are not publicly available. Any analysis requires previous application requests regarding access and processing conditions. (2) They exclusively represent the population of a given insurance with the risk of associated methodological challenges and bias (Schubert et al. 2014; Swart et al. 2015). An existing cross-insurance metadata pool, according to $\S 303 \mathrm{~d}$ SGB V (information system healthcare data [Informationssystem Versorgungsdaten]) (DIMDI 2014), does not currently contain information that enables the identification of LTIV patients. Therefore, assessing the healthcare needs of the specific patient group on a broader than single insurer level would entail considerable effort and resources. (3) In addition to the general validity problems of insurance data (Schubert et al. 2014), the potential and reliability of analyses on the specific patient group are questionable overall. Individual data requests for available information on LTIV from single insurers showed a substantial informational variability: whether the ventilation mode (noninvasive/invasive), condition, place of residence, and (comprehensive) healthcare utilization of LTIV patients is known depends on coding principles that vary between insurers (Stark et al. 2016).

\section{Discussion}

Our analysis of official data sources showed that information enabling the description of normative healthcare needs of LTIV patients based on (healthcare) epidemiological data are currently missing. None of the potentially eligible databases in the hospital and/or long-term care setting offers basic data on the patient group, except for the DRG statistics that will provide interventional clinical OPS codes on the initiation or control/optimization of invasive ventilation at home (DIMDI 2016) as of reporting year 2017. Our analysis is limited to officially available databases. It comprised neither a feasibility analysis of potentially eligible databases (DRG statistics, claims data, WeanNet registry) for needs assessment nor a 
detailed overview of their degree of differentiation. Rather, it provides an overview of current existing empirical data sources and the future steps needed.

Although the DRG statistics will enable the initial and ongoing (yearly) estimation and characterization of specific healthcare needs (home invasive ventilation) based on a complete inventory on a national and small area level, this statistic features some disadvantages: the data are limited to the hospital setting, do not contain vulnerability information, and are cut off by hospital discharge. Thus, they are merely a crude indicator of the epidemiology of LTIV in outpatient healthcare settings. The patient group cannot be followed up. Case-based OPS documentation, a significant patient mortality, and a comparatively low level of regular hospital follow-ups (Lehmann et al. 2016) impede realistic estimations on the incidence and prevalence after the initiation of home invasive ventilation. The necessary linkage with specific primary and secondary healthcare data is, as shown, limited by missing data sources and methodological challenges (Swart et al. 2015). In addition to these challenges, inferring the actual extent of the healthcare needs for the patient group is limited by an abbreviated understanding of how the severity of conditions affects the actual quality and quantity of needs (Lehmann et al. 2016).

These limitations provide important implications for further efforts regarding healthcare planning and regulations informed by the healthcare needs of LTIV patients:

\section{Address the limited eligibility of existing databases}

Future initiatives should address the epidemiological knowledge gap on LTIV patients, e.g., by utilizing or optimizing existing resources. Due to the limited scope or access and unique challenges of almost all existing databases, a unilateral extension of single resources (e.g., claims data, nursing care statistics) might be challenging. Rather, such approaches should incorporate a cross-sectoral perspective that addresses the multisectoral and interprofessional healthcare needs of LTIV patients. Thus, it is recommended to develop and harmonize specific indicators related to LTIV that enable the identification, characterization (e.g., morbidity, demographics), and classification (e.g., stratified by severity, vulnerability) of the patient group and their differing healthcare needs. This basic information should be supplemented by crosssectoral data on medical, therapeutic, and nursing health interventions utilization and the provision of medical supplies. Such information could facilitate data-informed regional needs-based healthcare planning and regulation by accountable self-governance bodies. In addition, specialized healthcare providers could tailor their services to these needs.
Due to the various advantages of claims data (e.g., local, cross-sectoral, patient-related, and continuous data on resource utilization), they are generally viewed as eligible to inform healthcare planning and regulation. The general challenges of this data source, such as missing coding standards, data access, restrictions on representativeness, or completeness (RKI 2011; Schubert et al. 2014), also apply to LTIV patients. It is, therefore, recommended to harmonize information on LTIV patients across health insurances. Access to this information should be supported through incorporation into the health insurance metadata pool according to $\S \S 303 \mathrm{a}-\mathrm{e}$ SGB V or the extensions of available inventories (e.g., KG 2, nursing care statistic).

Alternatively, the expansion of the WeanNet register of certified weaning centers might be promising. Already covering multifaceted inpatient data on epidemiology, healthcare, and outcomes of prolonged ventilation, this register could be adapted to the follow-up of patients with unsuccessful weaning and their long-term care. This would provide comprehensive information on (normative) health needs, long-term care settings and outcomes, enable comprehensive needs assessments, and support regular monitoring of the patient population in line with the German guidelines recommendations (DGP 2017). However, this approach necessitates the register's perspective to be extended from an inpatient healthcare quality to a cross-sectoral patient focus. Additionally, the register should cover all inpatient facilities offering specialized acute care for prolonged ventilation regardless of their certification status and provide public access to data.

\section{Expand view on the concept of healthcare needs}

The great heterogeneity of LTIV patients (Lloyd-Owen et al. 2005) requires knowledge of the potential diversity of healthcare needs. In addition to efforts to identify normative healthcare needs based on epidemiology, a broader view is required that accounts for patient-centeredness and needs orientation in healthcare. This would involve both individual perspectives (Godfrey and Callaghan 2000) and a view beyond the predominantly medical perspective on healthcare (SVR 2018). The fact that vulnerable patient groups feature a great complexity of continuing healthcare needs should be considered. A shortened perspective on morbidity and medical healthcare utilization does not appropriately represent this complexity and neglects fragmentation issues. Additional consideration of the multidimensionality of specialized healthcare in terms of cross-sectoral and multiprofessional approaches (e.g., nursing and therapeutic) would support a holistic, continuity perspective on healthcare and needs orientation (WHO 2015; SVR 2018). In practice, we need adequate answers to the questions on which specific patient 
(sub-)groups need what healthcare (type, range, amount) and how should the services needed be provided (quality).

\section{Identify and clarify reasonable actions to address healthcare needs}

Although the patient group is estimated to be small, their healthcare is resource-intensive and involves specific demands on the quantity (structure and distribution) and quality (processes and results) of specialized healthcare, as well as the qualifications of healthcare professionals. Thus, future research should answer fundamental questions based on the knowledge required about the healthcare needs of LTIV patients, but also comparable patient groups. It should be made clear how appropriate healthcare in the right place at the right time should be shaped. Additionally, current anecdotal evidence on unmet needs in terms of access, appropriateness, continuity, and quality of healthcare should be evaluated for its impact on outcomes and patient safety, as well as at the systems level. For their part, these findings should guide the planning, regulation, and provision of needs-based healthcare for LTIV patients.

\section{Conclusion}

Neither primary or secondary statistical data nor claims data are currently eligible to characterize the healthcare needs of long-term invasively ventilated (LTIV) patients beyond the acute care setting. Only the diagnosis-related groups (DRG) statistics provide hospital-specific data as of 2017, enabling OPS-based identification and description of the initial setup or control of cases of LTIV at home. Thus, valid information on the current and prospective patient population and their need for specific healthcare is currently lacking. These results imply that future improvements of the date availability and differentiation have to be undertaken to provide the basis for evidence-based approaches to needs-oriented specialized healthcare. Eligible approaches to needs assessment should consider the very heterogeneity, severity, and complexity of the healthcare needs of the patient group, including subjective dimensions on a life course perspective, as well as quantitative and qualitative service performance characteristics across multiple sectors and professions.

Acknowledgements This analysis was conducted within the health services research project "Healthcare for long-term ventilated patientsregional aspects" [VELA-Regio-Versorgungsangebote für langzeitbeatmete Patienten unter regionalen. Gesichtspunkten - eine Expertise] funded by Allgemeine Ortskrankenkasse-Bundesverband (AOK-BV), Germany.
Author contributions Michael Ewers (ME) contributed to the study design, conception, and development. Susanne Stark (ST) developed and conducted the research approach and analyzed the data. Both authors discussed and confirmed the results. ST drafted the manuscript. ME was responsible for the critical revision of the manuscript.

\section{Compliance with ethical standards}

Conflict of interest The authors declare that they have no conflict of interest.

\section{References}

Bradshaw J (1972) Taxonomy of social need. In: McLachlan G (ed) Problems and progress in medical care: essays on current research. Oxford University Press, London, pp 71-82

Bundesministerium für Gesundheit (BMG) (2017) Gesetzliche Krankenversicherung. Leistungsfälle und -tage 2016. https://www. bundesgesundheitsministerium.de/fileadmin/Dateien/3 Downloads/Statistiken/GKV/Geschaeftsergebnisse/KG2_2016.pdf. Accessed 19 Sep 2018

Daniels N (1981) Health care needs and distributive justice. Philos Public Aff 10:146-179

Deutsche Gesellschaft für Pneumologie und Beatmungsmedizin (DGP) (2017) S2k - Leitlinie. Nichtinvasive und invasive Beatmung als Therapie der chronischen respiratorischen Insuffizienz. Revision 2017. https://www.awmf.org/uploads/tx_szleitlinien/020-0081 S2k_NIV_Nichtinvasive_invasive_Beatumung_Insuffizienz_201710.pdf. Accessed 22 Aug 2018

Deutsche Interdisziplinäre Gesellschaft für Außerklinische Beatmung (DIGAB); Bund der Pneumologen (BdP); Deutsche Gesellschaft für Neurologische Intensivmedizin (DGNI); Deutsche Gesellschaft für Pneumologie und Beatmungsmedizin (DGP); Deutscher Hausärzteverband; Deutsche Interdisziplinäre Vereinigung für Intensivmedizin (DIVI); Verband Pneumologischer Kliniken (VPK) (2017) Positionspapier zur aufwendigen ambulanten Versorgung tracheotomierter Patienten mit und ohne Beatmung nach Langzeit-Intensivtherapie (sogenannte ambulante Intensivpflege). Pneumologie 71:204-206. https://doi.org/10.1055/ s-0043-104028

Deutsches Institut für Medizinische Dokumentation und Information (DIMDI) (2014) Informationssystem Versorgungsdaten (Datentransparenz): Datensatzbeschreibung. https://www.dimdi.de/ static/.downloads/deutsch/versorgungsdatendatensatzbeschreibung.pdf. Accessed 10 Sep 2018

Deutsches Institut für Medizinische Dokumentation und Information (DIMDI) (2016) OPS Version 2017. Operationen- und Prozedurenschlüssel Version 2017. https://www.dimdi.de/static/de/ klassifikationen/ops/kode-suche/opshtm12017/. Accessed 31 Jul 2018

Gemeinsamer Bundesausschuss (G-BA) (2018) Richtlinie des Gemeinsamen Bundesausschusses über die Verordnung von häuslicher Krankenpflege (Häusliche Krankenpflege-Richtlinie) in der Fassung vom 17. September 2009 zuletzt geändert am 19. Juli 2018. https://www.g-ba.de/downloads/62-492-1671/HKP-RL 2018-07-19_iK-2018-10-12.pdf. Accessed 10 Oct 2018

Gesundheitsberichterstattung des Bundes (GBE Bund) (2016) Operationen und Prozeduren der vollstationären Patientinnen und Patienten in Krankenhäusern (Wohnort/Behandlungsort). https:// www.destatis.de/DE/Publikationen/Thematisch/Gesundheit/ Krankenhaeuser/OperationenProzeduren5231401167014.pdf; jsessionid=90F469882D9D3F7CC6E2EB03831844F1. InternetLive1?_blob=publicationFile. Accessed 13 Sep 2018 
Godfrey M, Callaghan G (2000) Exploring unmet need. The challenge of a user-centred response. https://www.jrf.org.uk/file/36604/ download?token=aiFH3_0D\&filetype=full-report. Accessed 4 Sep 2018

Lehmann Y, Stark S, Ewers M (2016) Versorgung invasiv langzeitbeatmeter Patienten unter regionalen GesichtspunktenVELA-Regio. Teil 3: Strukturen und Prozesse aus Akteurssicht. Working Paper No. 16-03 der Unit Gesundheitswissenschaften und ihre Didaktik. Charité-Universitätsmedizin Berlin. https:// igpw.charite.de/fileadmin/user_upload/microsites/m_cc01/igpw/ Publikationen/Working-Paper/WP_16-03.pdf. Accessed 28 Oct 2018

Lewarski JS (2005) Long-term care of the patient with a tracheostomy. Respir Care 50:534-537

Lloyd-Owen SJ, Donaldson GC, Ambrosino N, Escarabill J, Farre R, Fauroux B, Robert D, Schoenhofer B, Simonds AK, Wedzicha JA (2005) Patterns of home mechanical ventilation use in Europe: results from the Eurovent survey. Eur Respir J 25:1025-1031. https:// doi.org/10.1183/09031936.05.00066704

Midgren B, Olofson J, Harlid R, Dellborg C, Jacobsen E, Nørregaard O (2000) Home mechanical ventilation in Sweden, with reference to Danish experiences. Respir Med 94:135-138. https://doi.org/10. 1053/rmed.1999.0699

Nasiłowski J, Wachulski M, Trznadel W, Andrzejewski W, Migdał M, Drozd W, Pytel A, Suchanke R, Czajkowska-Malinowska M, Majszyk T, Szkulmowski Z, Chazan R (2015) The evolution of home mechanical ventilation in Poland between 2000 and 2010. Respir Care 60:577-585. https://doi.org/10.4187/respcare.03126

Ozegowski S, Sundmacher L (2012) Wie "bedarfsgerecht" ist die Bedarfsplanung? Eine Analyse der regionalen Verteilung der vertragsärztlichen Versorgung. Gesundheitswesen 74:618-626. https://doi.org/10.1055/s-0032-1321748

Randerath WJ, Kamps N, Brambring J, Gerhard F, Lorenz J, Rudolf F, Rosseau S, Scheumann A, Vollmer V, Windisch W (2011) Recommendations for invasive home mechanical ventilation. Pneumologie 65:72-88. https://doi.org/10.1055/s-0030-1256121

Robert Koch-Institut (RKI) (2011) Kleinräumige Bedarfsprognosen Eine Machbarkeitsstudie für Deutschland. http://www. bundesaerztekammer.de/fileadmin/user_upload/downloads/ Bedarfsprognosen-1.pdf. Accessed 9 Oct 2018

Schönhofer B, Pfeifer M (2010) WeanNet - competence network of pneumology weaning centers. Patient register and accreditation of centers. Pneumologie 7:121-124. https://doi.org/10.1007/s10405009-0371-8

Schönhofer B, Geiseler J, Dellweg D, Moerer O, Barchfeld T, Fuchs H, Karg O, Rosseau S, Sitter H, Weber-Carstens S, Westhoff M, Windisch W (2014) Prolonged Weaning. S2k-guideline published by the German Respiratory Society. Pneumologie 68:19-75. https:// doi.org/10.1055/s-0033-1359038

Schubert I, Ihle P, Köster I, Küpper-Nybelen J, Rentzsch M, Stallmann C, Swart E, Winkler C (2014) Datengutachten für das Deutsche Institut für Medizinische Dokumentation und Information (DIMDI). Daten für die Versorgungsforschung. Zugang und Nutzungsmöglichkeiten. https://www.dimdi.de/static/.downloads/deutsch/dimdisekundaerdaten-expertise.pdf. Accessed 28 Aug 2018

Stark S, Lehmann Y, Ewers M (2016) Versorgung invasiv langzeitbeatmeter Patienten unter regionalen GesichtspunktenVELA-Regio. Teil 2: Bedarf und Strukturen. Working Paper No. 16-02 der Unit Gesundheitswissenschaften und ihre Didaktik. Charité—Universitätsmedizin Berlin. https://igpw.charite.de/ fileadmin/user upload/microsites/m cc01/igpw/Publikationen/ Working-Paper/WP_16-02.pdf. Accessed 28 Oct 2018

Sachverständigenrat zur Begutachtung der Entwicklung im Gesundheitswesen (SVR Gesundheit) (2014) Bedarfsgerechte Versorgung-Perspektiven für ländliche Regionen und ausgewählte Leistungsbereiche. Hans Huber, Bern

Sachverständigenrat zur Begutachtung der Entwicklung im Gesundheitswesen (SVR Gesundheit) (2018) Bedarfsgerechte Steuerung der Gesundheitsversorgung. https://www.svrgesundheit.de/fileadmin/user_upload/Gutachten/2018/SVRGutachten_2018_WEBSEITE.pdf. Accessed 6 Sep 2018

Statistisches Bundesamt (2017a) Krankenhausstatistik - Grunddaten der Krankenhäuser und Vorsorge- oder Rehabilitationseinrichtungen. Intensivmedizinische Versorgung in Krankenhäusern (Betten) sowie Aufenthalte (Behandlungsfälle und Berechnungs-/Belegungstage). Gliederungsmerkmale: Jahre, Region, Einrichtungsmerkmale. http://www.gbe-bund.de/oowa921-install/servlet/oowa/aw92/ dboowasys921.xwdevkit/xwd_init?gbe.isgbetol/xs_start_neu/\&p_ aid $=3 \& p \_a i d=80839547 \&$ nummer $=841 \& p \_s p r a c h e=D \& p$ indsp $=-\& p \_$aid $=72663831$. Accessed 19 Oct 2018

Statistisches Bundesamt (2017b) Pflegestatistik 2015. Pflege im Rahmen der Pflegeversicherung Ländervergleich-Pflegebedürftige. Statistisches Bundesamt: Wiesbaden

Statistisches Bundesamt (2018) Fallpauschalenbezogene Krankenhausstatistik. DRG-Statistik. Qualitätsbericht 2017. https:// www.destatis.de/DE/Publikationen/Qualitaetsberichte/ Gesundheitswesen/FallpauschaleKrankenhausstatistk.pdf? blob= publicationFile. Accessed 11 Sep 2018

Swart E, Ihle P, Gothe H, Matusiewicz D (eds) (2015) Routinedaten im Gesundheitswesen. Handbuch Sekundärdatenanalyse: Grundlagen, Methoden und Perspektiven. Hans Huber, Bern

Tollefsen E, Gulsvik A, Bakke P, Fondenes O (2009) Prevalence of home ventilation therapy in Norway. Tidsskr Nor Laegeforen 129:2094 2097. https://doi.org/10.4045/tidsskr.08.0716

World Health Organization (WHO) (2015) WHO global strategy on people-centred and integrated health services. http://apps.who.int/ iris/bitstream/10665/155002/1/WHO_HIS_SDS_2015.6_eng.pdf? ua $=1 \& u a=1$. Accessed 13 Sep 2018

Publisher's note Springer Nature remains neutral with regard to jurisdictional claims in published maps and institutional affiliations. 